\title{
ELECTROSPINNING PBAT (POLY (BUTYLENE-ADIPATE-CO-TEREPHTHALATE))/PCL (POLY(ع-CAPROLACTONE) BLEND CONTAINING PROPOLIS FOR THE PREPARATION OF A SMART WOUND DRESSING
}

\author{
Heloisa G. Zanella ${ }^{\mathrm{a}}$, Ariane R. Souza Rossina, Janice Caroline Hardt ${ }^{\mathrm{b}}$, Andressa G. Rosenberger ${ }^{\mathrm{b}}$, Juliana C. Wiggers, \\ Josiane Caetano ${ }^{\mathrm{b}}$ and Douglas C. Dragunski $\mathrm{i}^{\mathrm{a}, \mathrm{b}, \boldsymbol{J}, \odot}$
}

a'Departamento de Química, Universidade Estadual de Maringá, 87020-900 Maringá - PR, Brasil

bUniversidade Estadual do Oeste do Paraná, 85903-000 Toledo - PR, Brasil

Recebido em 18/02/2021; aceito em 01/06/2021; publicado na web em 22/06/2021

\begin{abstract}
The electrospinning has been widely used in tissue engineering for the preparation of wound dressing with the most varied polymers and drugs. Considering that propolis has antimicrobial and anti-inflammatory characteristics, the aim was to develop electrospun fibers from PBAT (poly (butylene-adipate-co-terephthalate)/PCL (poly( $\varepsilon$-caprolactone) containing propolis in order to promote antimicrobial action and the healing of wounds. By the optical microscopy analysis, the best parameter for obtaining the fibers was chosen: $16.5 \%(\mathrm{v} / \mathrm{v})$ of propolis extract alcoholic solution, $14.0 \mathrm{~cm}$ needle-collector distance, $17.0 \mathrm{kV}$ of voltage and $0.5 \mathrm{~mL} \mathrm{~h}^{-1}$ flow rate. The scanning electron microscopy demonstrated fiber diameters of $0.51 \pm 0.12 \mu \mathrm{m}$ for the polymer blend and $1.16 \pm 0.98 \mu \mathrm{m}$ for the blend with propolis. The Fourier transform infrared spectroscopy (FTIR) results showed no evidence of chemical interaction with propolis, this being a physical interaction. This interaction was corroborated by the differential scanning calorimetry (DSC) due to the variation in the heats involved, mainly in the aromatic part of the polymer blend, indicating a better interaction in the PBAT group. Finally, it was found that fibers presents propolis antimicrobial activity against the bacteria Pseudomonas Aeruginosa. The results indicate that this blend has a great potential to be used as a cutaneous dressing.
\end{abstract}

Keywords: electrospun; antimicrobial; wound dressing.

\section{INTRODUCTION}

Wound healing is an extremely complex and important biological process that goes through several physiological steps until an appropriate final result. The several stages of this process include the tissue reconstrution and replacement, prevention of bleeding, the inflammatory response, the interaction of multiple sells and regulators, which can always play appropriate roles to ensure healing. Many current studies seek improve the chronic wounds healing. ${ }^{1-4}$ Therefore, the search for effective and safe healing agents is a major concern. ${ }^{4}$

Usually, the "modern dressings" can be applied as a way to assist in this process and to innovate the environment in which the wound will be exposed. It means allowing oxygen to enter and preventing contamination and dryness, good stability, antimicrobial properties, vascularization, biodegradability, among others. ${ }^{5,6}$ Among the most varied segments that can be applied for dressing production, the electrospinning, a technique for polymeric matrices production on a nano/micrometric scale draws attention. This happens because this techonology is capable of providing the injured tissue with growth and cell differentiation, adhesion, migration and adequate morphological characteristics. ${ }^{7,8}$ In addition, the electrospinning is a simple, cost-effective and versatile method, which creates a porous surface that mimics the extracelular matrix, thus, providing a favorable environment for studies. ${ }^{9,10}$

Besides the electrospun matrices, the poly (butylene adipate-coterephthalate) (PBAT) could be used. The PBAT is commercially known as Ecoflex ${ }^{\circledR}$, an aromatic aliphatic polyester with low cristallinity, high flexibility, high biodegradability, biocompatibility, and high elongation and strength. ${ }^{11,12}$ Currently, the search for the use of electrospun matrices in the biomedical area is very large and requested by scientists. The objectives of studies are varied, from cancer prevention ${ }^{13}$ to wound healing ${ }^{2}$ and others. ${ }^{14-17}$ The

*e-mail: dcdragunski@gmail.com applications in vivo are still not explored enough, but it is a promising alternative. ${ }^{18}$ Schneider et al. ${ }^{19}$ evaluated the electrospinning PBAT/ PLA (poly(lactic acid)) with an antibiotic used in carriers medication and dressing, observing nanofibers with uniform distribution. The authors concluded that the material was able to provide a rapid release of the antibiotic and inhibit the growth of Staphylococcus aureus bacteria.

Single component electrospun nanofibers may have limitations on their functions. Several studies in scientific literature explore different polymers association to improve characteristics such as biocompatibility and mechanical properties. ${ }^{20-23}$ With the same objective, polymers such as poly( $\varepsilon$-caprolactone) (PCL) ${ }^{24}$ and compounds with biological properties such as propolis are used. ${ }^{25}$ The PCL is considered to be a very versatile biodegradable polymer in the medical field and it has been extensively studied by tissue engineering for regeneration and wound healing. ${ }^{26}$ The production of nanofibers by the electrospinning technique using the PCL is widely studied as it provides a large surface area and good conditions for cell proliferation, besides the great affinity with biological tissue. ${ }^{27}$ One of the major problems of aliphatic polyester, such as PCL, is the stiffness and high crystallinity, which can decrease its effectiveness in vivo tests. On the other hand, associated with other materials can confer positive results. ${ }^{18}$

Besides a compatible polymeric matrix, it is possible to add other substances to these polymers, thus, improving wound healing capability. For example, propolis is a substance produced by bees. It is collected from plants, mixed with bee salivar enzymes and then applied to the combs and walls of the hive, making the environment aseptic. ${ }^{28}$ This has known antibiotic and antifungal activity in the medical, pharmaceutical and cosmetic areas. ${ }^{28,29}$ Propolis has great medicinal and therapeutic value due to its diverse properties to humans. Such as its antimicrobial, antiallergenic, antifungal, antiviral, antioxidant, anti-inflammatory and anticancer activity. Besides, it has high adhesive properties, that can influence in electrospun matrices 
morphology and mechanical properties..$^{30,31}$ Its is currently applied in the pharmaceutical and cosmetics industry, and its used has increased as a nutraceutical, in functional food and food supplements to promote health. ${ }^{28,32}$

The chemical composition of propolis is complex and its biological activity depend on the flora available to bees in specific geographical areas. Raw propolis is mainly composed of plant resins, oil, pollen essential, amino acids, minerals, sugars, vitamin B, C and E, flavonoids, phenol and aromatic compound. ${ }^{33,34}$ The active constitution (flavonoids) of propolis on the surface of the electrospun matrices adds additional functionalities for the electrospun matrices. ${ }^{35}$ Investigations of the use electrospun matrices incorporated with propolis for use in dressing have already been presented in the literature and with promising results. ${ }^{36,37}$

Therefore, the objective of this study is to prepare electrospun material with of PBAT and PCL as a polymeric matrix and propolis (Prop) as an antifungal and antibiotic agent, searching for a low cost and easy to handle material to use as smart transdermal dressing for wound healing.

\section{EXPERIMENTAL SECTION}

\section{Reagents}

Polymers used in the experiments: poly(butylene adipate-coterephthalate) (PBAT) (molar mass: $\left.6.6 \times 10^{5} \mathrm{~g} \mathrm{~mol}^{-1}\right)$ produced by Basf (Germany) and poly $\varepsilon$-caprolactone (PCL) (molar mass: $\left.8 \times 10^{5} \mathrm{~g} \mathrm{~mol}^{-1}\right)$, chloroform ( $\left.\geq 99.8 \%\right)$, N,N-dimethylformamide ( $\geq 99.8 \%$ ) (DMF) acquired from FMaia (Brazil), alcoholic propolis extract (Propolina Breyer - 12\% dry propolis extract and $88 \%$ neutral cereal alcohol) acquired in a local pharmacy of Toledo - PR (Brazil).

\section{Electrospinning}

The experimental section was conducted based on the study of the Kim, J. I. and collaborators. ${ }^{35}$ The polymeric solution was prepared by dissolving of $1.0 \mathrm{~g}$ of PBAT/PCL in the proportion of 75/25 (v/v) in a mixture of chloroform $(3.75 \mathrm{~mL})$ and DMF $(1.25 \mathrm{~mL})$. Then, $1.0 \mathrm{~mL}$ alcoholic propolis extract Propolina Breyer was added, which corresponded to $16.5 \%(\mathrm{v} / \mathrm{v})$ of the pure substance in the solution. Afterwards, in ambient temperature $\left(25 \pm 3{ }^{\circ} \mathrm{C}\right)$, the solution was kept under mechanical agitation for 24 hours. Other two solutions of $5.0 \%$ and $30.0 \%(\mathrm{v} / \mathrm{v})$ propolis were also prepared following the same methodologies.

In order to obtain the PBAT/PCL electrospun matrices, the tested parameters were: voltage of $14.0,17.0,18.0$ and $22.0 \mathrm{kV}$ and needlecollector distance of $12.0 \mathrm{~cm}, 14.0 \mathrm{~cm}$ and $15.0 \mathrm{~cm}$. The solution flow was kept constant at $0.5 \mathrm{~mL} \mathrm{~h}^{-1}$, and this parameter was chosen through previous studies in the research group. The pure polymer mixture solutions (reference sample) and the polymer mixture solution incorporated with propolis were subjected to electrospinning. After that, the electrospun matrices were kept in a desiccator for 3 days for residual solvent removal. The Figure $1 \mathrm{~S}$ shows a schematic illustration of electrospinning step in the experimental section.

\section{Characterization}

The electrospun matrices morphology and uniformity were analyzed using glass sheets that had been taped to the surface of the collector. The fibers formation began after a few seconds and then broke off. After that, the sheets were analyzed in an Olympus optical microscopy, model cx31 in order to choose the best parameters for the electrospinning. Subsequently, the membrane was formed and analyzed using scanning electron microscope (SEM), Tescan - model Vega3. In order to make the samples electrically conductive, they were deposited on double sided carbon adhesive tape and metallized with gold to a thickness of $30.0 \mathrm{~nm}$. The images were obtained by applying an electron acceleration voltage ranging from 12.0 to $20.0 \mathrm{kV}$. The average diameters of 100 measurements were determined by the ImageJ software.

The functional groups of the electrospun matrices, as well as the incorporation of propolis in the electrospun matrices were evaluated by Fourier transform infrared spectroscopy (FTIR). The FTIR spectrum was obtained with Perkin-Elmer spectrophotometer using the attenuated Total Reflectance (ATR) in the scan values in the range of $600 \mathrm{a} 4000 \mathrm{~cm}^{-1}$, with a resolution of $2.0 \mathrm{~cm}^{-1}$ at $25{ }^{\circ} \mathrm{C}$.

The electrospun matrices thermal properties were analyzed by means of differential scanning calorimetry (DSC) curves. The DSC curves were obtained with a DSC-50 da Shimadzu with nitrogen atmosphere, with nitrogen flux of $50.0 \mathrm{~mL} \mathrm{~min}^{-1}$, heating ramp of of $10.0{ }^{\circ} \mathrm{C} \mathrm{min}{ }^{-1}$, cooling rate $-10.0{ }^{\circ} \mathrm{C} \mathrm{min}-1$, temperature ranging from 30.0 to $200.0^{\circ} \mathrm{C}$ and 200.0 to $30.0^{\circ} \mathrm{C}$, partially closed aluminum capsule and sample mass of approximately $6.0 \mathrm{mg}$. The values of melting temperature, crystallization and their enthalpies were obtained using the software (TA-60WS). The percentage of cristallinity was obtained using Equation $1 .^{38}$

$$
X_{c}=\frac{\Delta H_{m}-\Delta H_{c c}}{\Delta H_{m}^{o}} \times 100
$$

In which: $\mathrm{X}_{\mathrm{C}}$ is the percentage crystallinity; $\Delta \mathrm{H}_{\mathrm{m}}$ is the enthalpy of fusion; $\Delta \mathrm{H}_{\mathrm{CC}}$ is the enthalpy of crystallization and $\Delta \mathrm{H}_{\mathrm{m}}{ }^{0}$ is the theoretical enthalpy of the $100 \%$ crystalline sample $\left(\Delta \mathrm{H}_{\mathrm{m}}{ }^{0}\right.$ of the PBAT is equal to $115.0 \mathrm{~J} \mathrm{~g}^{-139,40}$ and $\Delta \mathrm{H}_{\mathrm{m}}{ }^{0}$ of the PCL is equal to $\left.139.5 \mathrm{~J} \mathrm{~g}^{-138}\right)$.

\section{Antimicrobial activity}

A stock suspension solution of the bacterium Pseudomonas Aeruginosa (ATCC 7853) was prepared in glycerol and maintained at a temperature of $-20.0{ }^{\circ} \mathrm{C}$. Preliminary studies had been carried out previously to determine the minimum inhibitory concentration (MIC). The antimicrobial activity of electrospun matrices against Pseudomonas Aeruginosa was determined by the agar disc diffusion method. The disc control used in the test was the antibiotic kanamycin $(10.0 \mu \mathrm{g})$.

The isolation temperature of the colonies was $37.0 \pm 2.0^{\circ} \mathrm{C}$ for 20 hours in an orbital shaker. Then, the plating was performed in Petri dishes, so that the filter paper discs $(90.0 \times 15.0 \mathrm{~mm}$ in diameter) were distributed for the static growth of the bacterium in Luria-Bertani broth (LB) and agar culture medium, for 20 hours in a sterile oven at $37.0 \pm 2.0^{\circ} \mathrm{C}$. The plates were incubated in a sterile oven $37.0 \pm 2.0^{\circ} \mathrm{C}$ for 24 hours. The diameter of the inhibition zone was measured after incubation.

\section{RESULTS AND DISCUTION}

\section{Optical microscopy}

Initially, an attempt was made to use a pure dry propolis extract, but it presented a difficult solubilization. Bilginer and Yildiz ${ }^{41}$ evaluated the electrospinning of polyvinyl alcohol (PVA) enriched with propolis for biomedical applications and tissue engineering. The authors highlight this limitation in solubility in organic solvents and water, as well as in the clinical applications and bioavailability of propolis and atribute this to the lipophilic content of the substance. Therefore, in this study, an attempt was made to use an alcoholic 
propolis extract, which presented the desired solubility, making the formation of the electrospun matrices possible.

The concentrations of alcoholic propolis extract chosen for this study came from those applied by Kim et al. ${ }^{35}$ using polyurethane (PU) as a polymer, with promising results. Unlike the results found by the authors mentioned above, for the PBAT/PCL blend, for the concentration of $30.0 \%(\mathrm{v} / \mathrm{v})$ propolis extract, the formation of threads was not observed. Therefore, only the concentrations $16.5 \%$ and $5.0 \% \mathrm{v} / \mathrm{v}$ were maintained for the optimization of parameters. Also, some parameters that influence the morphology of the electrospun matrices were analyzed which were: the tension, needle-collector distance and the concentration of propolis extract. The flow rate was kept at fixed in $0.5 \mathrm{~mL} \mathrm{~h}^{-1}$.

The threads formation was observed in both studied concentrations $(5.0$ and $16.5 \% \mathrm{v} / \mathrm{v})$, with the presence of more prominent beads for the concentration of $5.0 \%$ propolis. The average diameters of reference sample were $0.51 \pm 0.12 \mu \mathrm{m}$. The best parameters obtained were those containing a concentration of propolis solution of $16.5 \% \mathrm{v} / \mathrm{v}$, a needlecollector distance of $14.0 \mathrm{~cm}$ and voltage of $17.0 \mathrm{kV}$, in comparison with the other parameters. According to Ramakrishna et al. ${ }^{42}$ the best parameter for the polymeric matrix formation is that it must present homogeneous fibers, of smaller diameter and without the presence of beads. The beads are structural "defects". This occurs when determined regions of the electrospun matrices show a slight increase in diameter and the matrix returns to small diameter again. The best parameter was designated as PBAT/PCL/Prop.

\section{Scanning Electron Microscopy (SEM)}

Figure 1 shows SEM images for PBAT/PCL (reference sample) and PBAT/PCL/Prop (sample incorporated with propolis) of electrospun membranes with magnification of 20000 times. After the insertion of propolis, the electrospun matrices produced have increased in diameter, however, they presented few beads. According to Rossin et al. ${ }^{43}$ the morphology of the electrospun matrices may depend on many factors such as viscosity, concentration, conductivity and others. In this case, the higher conductivity provided by the propolis extract, promoted a more uniform stretching generating a homogeneity of the electrospun matrices when compared to the pure blend. Mean diameter of the electrospun matrices were calculated using the ImageJ software and another predominant factor is the increase in average diameter from $0.51 \pm 0.12 \mu \mathrm{m}$ for $1.16 \pm 0.98 \mu \mathrm{m}$ for PBAT/PCL/Prop in comparison to PBAT/PCL. Asawahame et al. ${ }^{25}$ observed the same behavior for electrospun matrices with polymeric matrix of polyvinylpyrrolidone (PVP) K90 and $8.0 \%$ of alcoholic propolis extract. The increase in the diameter of electrospun matrices is due to the change in viscosity and the repulsive forces of the components dissolved in the propolis extract.

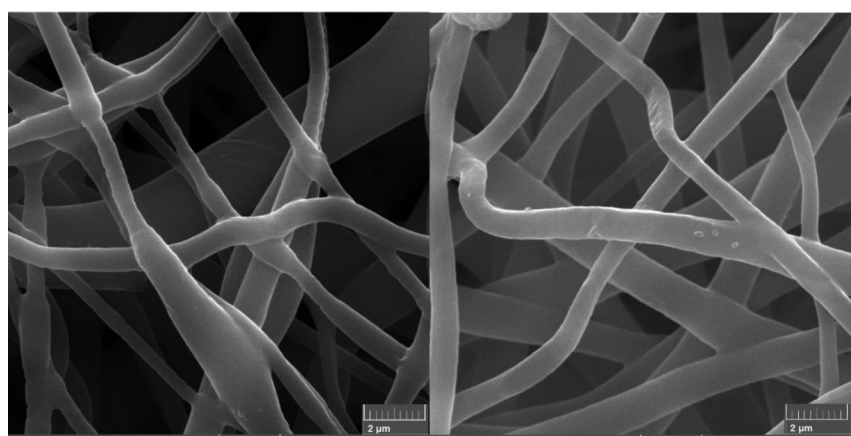

Figure 1. SEM images of the blend PBAT/PCL and PBAT/PCL/Prop with magnification of 20000 times
With the measurement of the diameters, it was possible to plot a graph of distribution of the particles sizes, indicated in Figure 2, that presents the diameters of the electrospun matrices (reference sample) and Figure 3 which presents the diameters of the electrospun matrices incorporated with the propolis. The distribution electrospun matrices diameter size indicated that the propolis affects the morphology of the electrospun matrices. In the electrospun matrices distribution (reference sample) the diameters of the nanowires vary from 0.2 to $1.3 \mu \mathrm{m}$ with a greater incidence in nanowires with diameters of approximately $0.6 \mu \mathrm{m}$. With the incorporation of propolis, the diameters vary between 0.5 to $3.3 \mu \mathrm{m}$, with a greater incidence in diameters of approximately $1.3 \mu \mathrm{m}$.

The obtained electrospun matrices presented large surface area, this can be an efficient drug delivery system. In this condition, the polymer have additional advantagens such as the ease of incorporating of carriers immobilized antibiotics and antimicrobials. ${ }^{44}$

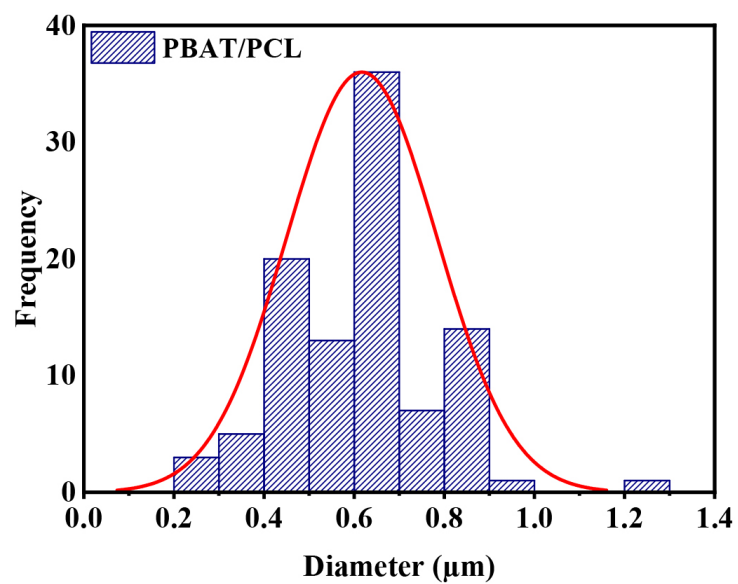

Figure 2. Size distribution of electrospun matrices of PBAT/PCL (reference sample)

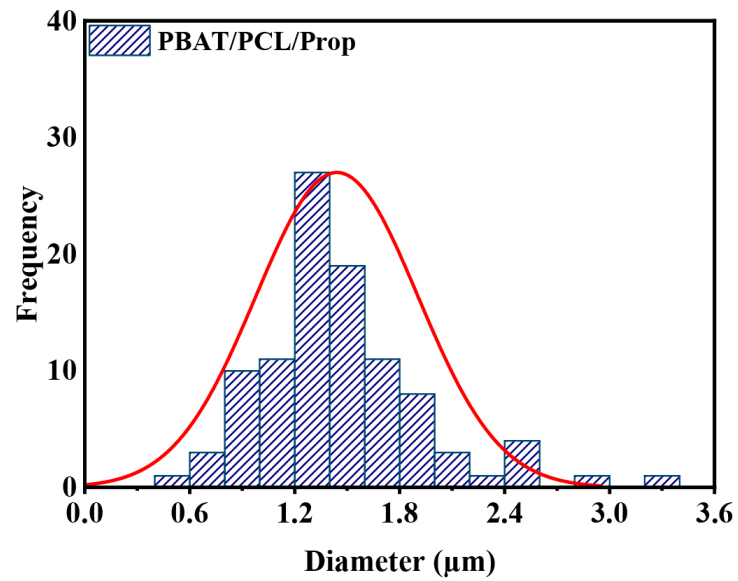

Figure 3. Size distribution of electrospun matrices incorporated with propolis

\section{Fourier transform infrares spectroscopy (FTIR)}

Figure 4 shows the spectra of the pure polymers that constitute the polymeric blend and Figure 5 shows the FTIR spectra obtained by the electrospun matrices (PBAT/PCL), the electrospun matrices incorporated with propolis and the alcoholic propolis extract spectra. Both polymers, PBAT and PCL have bands that are located in regions of the spectrum overlap, between $1600-2000 \mathrm{~cm}^{-1}$. The characteristic band of the PCL is vibrations near to $1700 \mathrm{~cm}^{-1}$ a band assigned to $\mathrm{C}=\mathrm{O}$ of the carbonyl of the PCL structure..$^{45,46}$

For PBAT, the main bands are in $\approx 3000 \mathrm{~cm}^{-1}$ which corresponds 


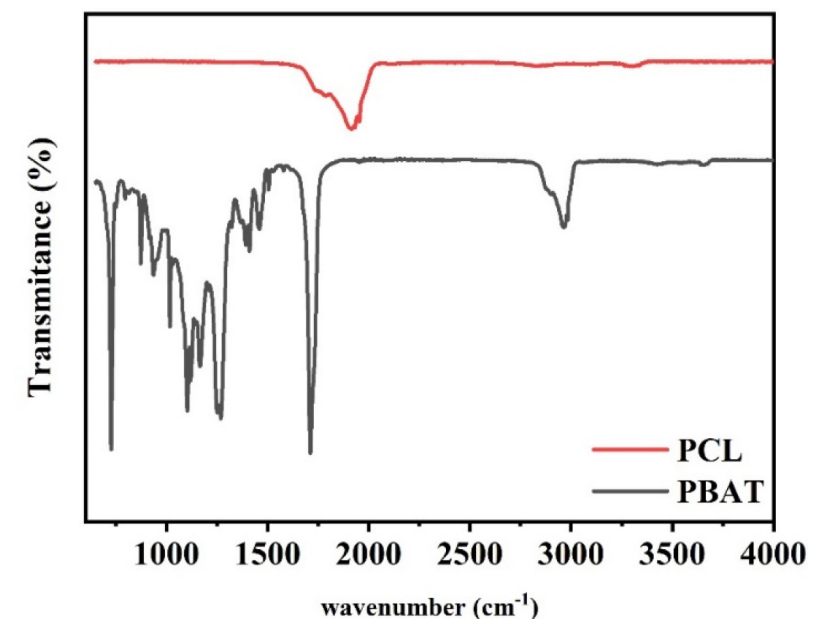

Figure 4. FTIR spectra of pure polymers, PCL (red curve) and PBAT (black curve)

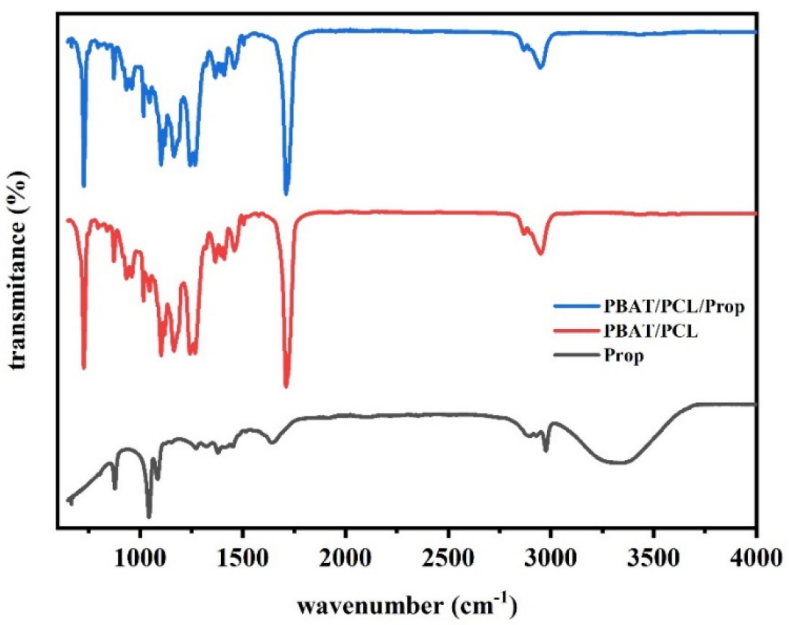

Figure 5. FTIR spectra obtained from electrospun matrices (PBAT/PCL) incorporated with propolis (blue curve); pure electrospun matrices (PBAT/ $P C L)$ (red curve) and alcoholic propolis extract (black curve)

to the $\mathrm{C}-\mathrm{H}$ stretches of $\mathrm{CH}_{2}$ bonds of the aliphatic and aromatic groups, in $\approx 1700 \mathrm{~cm}^{-1}$ which refers to the $\mathrm{C}=\mathrm{O}$ vibration of the carbonyl group, near to the $1400 \mathrm{~cm}^{-1}$ band which can be attributed to the a phenyl bonds, $\mathrm{C}$ linked to the aromatic part of the chemical structure of PBAT and in $\approx 1100 \mathrm{~cm}^{-1}$ which refers to the vibration of stretches of the C-O bond. ${ }^{47,48}$

The propolis has a lot of functional groups in its formulation, which makes it complex to be analyzed separately. Similarly, for the spectra of the alcoholic extract of propolis, there is a wide band in $3300 \mathrm{~cm}^{-1}$ which refers to the $\mathrm{OH}$ bond of phenolic and ethanolic groups, between 800 and $1000 \mathrm{~cm}^{-1}$ refers to vibration of $\mathrm{C}-\mathrm{H}$ bonds; in $1640 \mathrm{~cm}^{-1}$ band, which probably refers to the $\mathrm{C}=\mathrm{O}$ bond of the propolis flavonoids groups. ${ }^{33}$ The 2972, 1386 and $1086 \mathrm{~cm}^{-1}$ bands refer, respectively, to $\mathrm{C}-\mathrm{H}$ stretches of the $\mathrm{CH}_{2}$ bonds, the vibration of the $\mathrm{C}=\mathrm{C}$ bonds, and the stretch of $\mathrm{C}-\mathrm{O}$ bonds which refer to ester groups (R-COO-R'). ${ }^{48}$ Table 1 shows the compounds chemical structures, stretches and corresponding functional groups of the FTIR bands.

When analyzing the three FTIR spectras, it was possible to observe that no new bands appeared in the spectra of the electrospun matrices associated with propolis. Thus, this brings evidence that there was no chemical bond with the electrospun matrices and the interaction between them was physical.

\section{Differential scanning calorimetry (DSC)}

The DSC curves of the pure polymers (PBAT and PCL) are presented in Figure 6. Analyzing the DSC curves of pure polymers, a slight decrease in the melting temperature (Tm) of the pure polymers is observed when they are mixed, being for the PCL from 65.0 to $54.0{ }^{\circ} \mathrm{C}$ and for the PBAT from 121.0 to $115.0^{\circ} \mathrm{C}$. The crystallization temperatures increased slightly from 38.0 to $75.0^{\circ} \mathrm{C}$ for PCL and decreased from 122.0 to $71.0{ }^{\circ} \mathrm{C}$ for PBAT. The PBAT is a polymer that has high biodegradability and flexibility ${ }^{20}$ and PCL adds elasticity to the material due to the low glass transition temperature $(\mathrm{Tg})$, $\approx 60.0{ }^{\circ} \mathrm{C} .{ }^{49}$ Both are biodegradable, what offers the material an environmental importance and characteristics different from those of its individual polymers. Sousa, et. al. ${ }^{50}$ studied the thermal behavior of the PCL/PBAT mixture and the results showed a strong interaction between these polymers, where the presence of each component favors the crystallization of the other.

Figure 7 presents the DSC curves of the electrospun matrices, which confirmed possible changes in the material structure. The endotermic peaks shown refers to the melting temperature $\left(\mathrm{T}_{\mathrm{m}}\right)$ of the polymer constitutes the blend. At $55.0^{\circ} \mathrm{C}$ the peak refers to $\mathrm{PCL}^{50}$ and at $117.0{ }^{\circ} \mathrm{C}$ to $\mathrm{PBAT}^{50}$. After heating to $200.0^{\circ} \mathrm{C}$, the samples were cooled at rate $10.0{ }^{\circ} \mathrm{C} \mathrm{min}^{-1}$. The exothermic episode observed

Table 1. Compounds chemical structure, stretches and corresponding functional groups of the FTIR bands

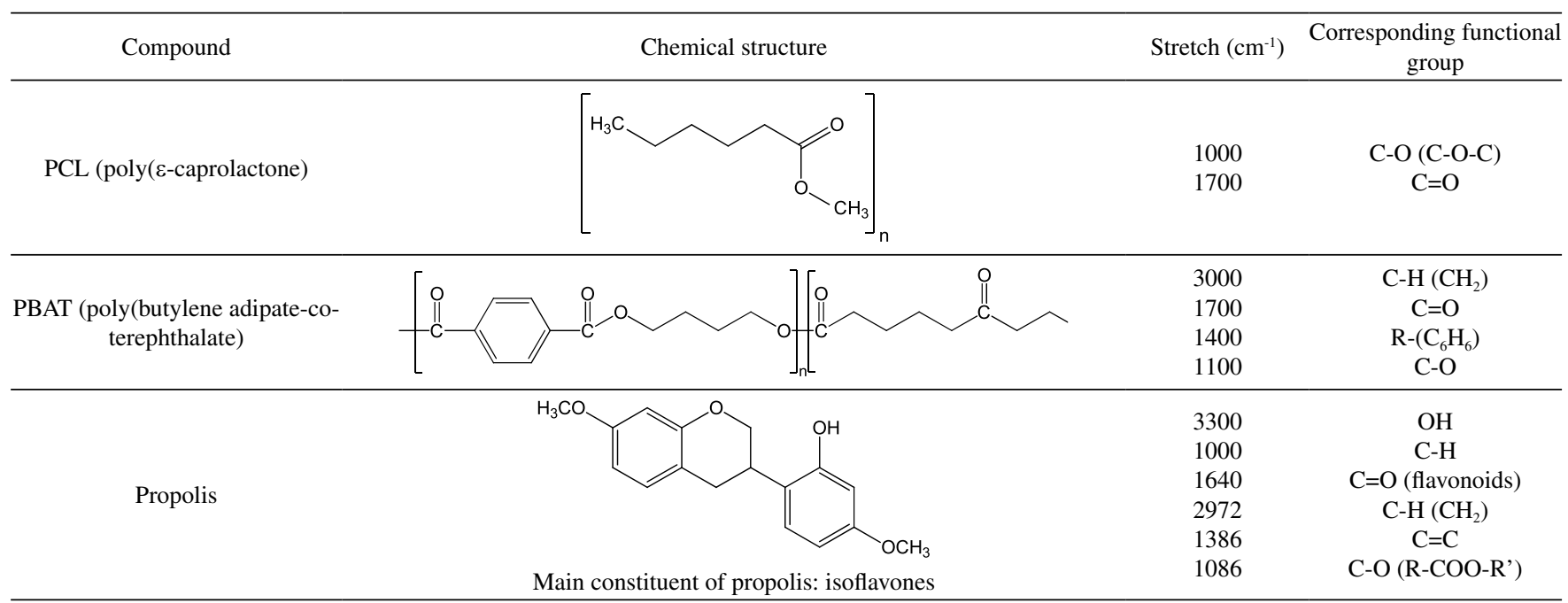




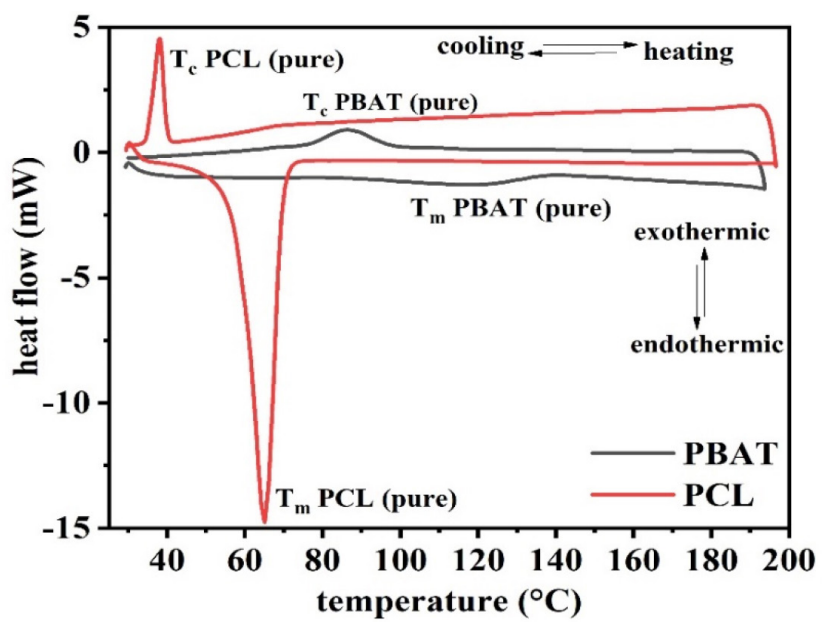

Figure 6. DSC curves for the pure polymers. Conditions used for heating and cooling: $10.0^{\circ} \mathrm{C} \mathrm{min}^{-1}$. Conditions for electrospinning: needle-collector distance: $14.0 \mathrm{~cm}$, flow rate: $0.5 \mathrm{~mL} \mathrm{~h}^{-1}$, voltage: $17.0 \mathrm{kV}$

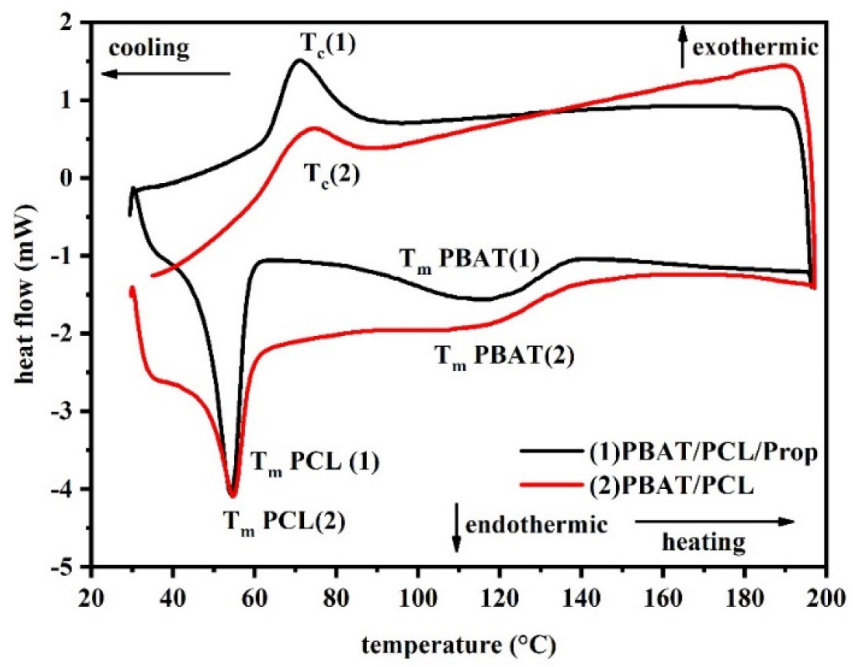

Figure 7. DSC curves for PBAT/PCL electrospun matrices. Conditions used for heating and cooling: $10.0{ }^{\circ} \mathrm{C} \mathrm{min}^{-1}$. Conditions for electrospinning: needle-collector distance: $14.0 \mathrm{~cm}$, flow rate: $0.5 \mathrm{~mL} \mathrm{~h} \mathrm{~h}^{-1}$, voltage: $17.0 \mathrm{kV}$

at approximately $71.0{ }^{\circ} \mathrm{C}$ refers to the crystallization temperature $\left(\mathrm{T}_{\mathrm{c}}\right)$ of PBAT. ${ }^{51}$

Table 2 shows the crystallinity, melting temperature and crystallization of the electrospun matrices with and without the incorporation propolis and the respective heats involved in the process.

Table 2. Cristallinity, melting temperatures and crystallization of the polymer electrospun matrices with and without the incorporation propolis and the respective heats involved

\begin{tabular}{cccc}
\hline Samples & $\mathrm{T}\left({ }^{\circ} \mathrm{C}\right)$ & Enthalpy $\left(\mathrm{J} \mathrm{g}^{-1}\right)$ & Cristallinity (\%) \\
\hline $\mathrm{T}_{\mathrm{m}}$ PCL (2) & 54.0 & 22.0 & 22.0 \\
$\mathrm{~T}_{\mathrm{m}}$ PBAT (2) & 117.0 & 9.3 & 24.0 \\
$\mathrm{~T}_{\mathrm{c}}(2)$ & 75.0 & -18.0 & \\
\hline $\mathrm{T}_{\mathrm{m}}$ PCL (1) & 55.0 & 23.0 & 19.4 \\
$\mathrm{~T}_{\mathrm{m}}$ PBAT (1) & 115.3 & 14.4 & 27.0 \\
$\mathrm{~T}_{\mathrm{c}}(1)$ & 71.0 & -16.0 & \\
\hline
\end{tabular}

According to the data in Table 2, it is observed the melting temperature and heat involved in the PBAT and the crystallization of the electrospun matrices and with the incorporation of propolis.
The melting temperature of PBAT remained constant, from 117.0 to $115.0{ }^{\circ} \mathrm{C}$ (Figure $4 \mathrm{~S}$ and $5 \mathrm{~S}$ supplementary material). and the heat involved increased from 9.3 to $14.4 \mathrm{~J} \mathrm{~g}^{-1}$. The values of enthalpy and melting temperature are similar for PCL, however for PBAT with the insertion of propolis, there was an increase in the melting temperature and is enthalpy, suggesting a possible interaction in this part of polymer blend.

As far as the authors as concerned, there are no reports in the scientific literature of electrospun membranes with PBAT and propolis, and thus, it was not possible to compare and confirm the interactions found with scientific data from other studies. However, considering that the temperatures and heats involved in the PCL did not change and also that the aliphatic part of the functional groups are similar to the aliphatic part of the PBAT, the interactions possibly occour more strongly in the PBAT functional groups (Figure $2 \mathrm{~S}-$ supplementary material).

The crystallization temperature remained constant with the incorporation of propolis, from 75.0 to $71.0{ }^{\circ} \mathrm{C}$. The electrospun matrices also presented a constant value for crystallinity, from 24.0 to $27.0 \%$ for PBAT and 19.4 to $22.0 \%$ for PCL. The crystallinity is an important influence on the mechanical, physical and chemical properties of the material. For example, high crystallinity can result in stronger polymer chains, less flexibility and higher thermal stability. ${ }^{52}$

\section{Antimicrobial activity}

Antimicrobial effects of the synthesized electrospun matrices were tested using the agar diffusion method. The tested bacterium was Pseudomonas Aeruginosa, a drug resistant bacterium which affects patients with debilitated imune systems when it comes into contact with the skin and that is susceptible of infection. ${ }^{53}$ The effects of propolis on the electrospun matrices of the antimicrobial sensibility test are shown in Figure 3S (supplementary material). Disc A contains $10.0 \mu \mathrm{g}$ of kanamycin (antibiotic), disc B refers to the polymeric control disc of PBAT/PCL and disc $\mathrm{C}$ to refers of the PBAT/PCL/Prop.

On disc $\mathrm{A}$ there is a high bacterial sensibility with approximately $3.0 \mathrm{~mm}$ of sterile halo, on disc B it is not possible to indentify any sterile halo, indicating that it is resistant. Disc C shows an inhibition halo, with a width of approximately $0.5 \mathrm{~mm}$, indicating that disc can be classified with intermediate bacterial sensibility.

The sensibility test is assessed according to the inhibition zone and can be sensitive, intermediate and resistant. The high sensibility indicates an inhibition of the in vitro growth of the bacteria by the antimicrobial agent. The intermediate sensibility indicates antimicrobial with therapeutic applicability when in high doses and the resistant ones indicate that there is an inhibition of bacterial growth in vitro by tested antimicrobial agent. ${ }^{54}$ The therapeutic sensibility of the electrospun matrices with propolis is given by the different constituents of propolis, such as flavonoids and derivatives of cinnamic acid. ${ }^{35}$

Therefore, it can be said that the polymer electrospun matrices incorporated with propolis have a high potential for making new dressings and promoting wound healing.

\section{CONCLUSIONS}

This study indicates for the first time the production of PBAT/ PCL fibers incorporated with propolis through the electrospinning technique. The characterization analyzes were performed using different techniques that indicate that propolis was successfully incorporated into the electrospun matrices. The obtained electrospun matrices presented large surface area, this can be an efficient drug delivery system. The DSC analyze was realized and the values 
remained constants with incorporation of propolis. This results corrobored with FTIR, which suggest the interactions of propolis with the electrospun matrices occurred physically with the polymeric blend. The antimicrobial activity of the electrospun matrices was also evaluated, which was shown to be moderate. The results indicate that the electrospun matrices are promising for use as scaffolds for dressing, presenting funcionality in wound healing.

\section{SUPPLEMENTARY MATERIAL}

Some images of the systems used in this study are available at http://quimicanova.sbq.org.br, as a free access PDF file.

\section{ACKNOWLEDGMENTS}

This study was supported by UNIOESTE. The authors would like to thank CNPq (National Conuncil for Science and Technological Development) and CAPES (Coordination of Improvement of Higher Educations Personnel)

\section{REFERENCES}

1. Toleubayev, M.; Dmitriyeva, M.; Kozhakhmetov, S.; Sabitova, A.; Ann. Med. Surg. 2021, 65.

2. Kalva, S. N.; Augustine, R.; Al Mamun, A.; Dalvi, Y. B.; Vijay, N.; Hasan, A.; J. Drug Deliv. Sci. Technol. 2021.

3. Pan, L.; Zhang, X.; Gao, Q.; J. Tissue Viability 2021, 30, 190.

4. Seyedian, R.; Isavi, F.; Najafiasl, M.; Zaeri, S.; J. Drug Deliv. Sci. Technol. 2021, 63, 102528.

5. Li, H.; Williams, G. R.; Wu, J.; Wang, H.; Sun, X.; Zhu, L. M.; Mater. Sci. Eng., C 2017, 79, 245.

6. Fahmy, A.; Kamoun, E. A.; El-Eisawy, R.; El-Fakharany, E. M.; Taha, T. H.; El-Damhougy, B. K.; Abdelhai, F. P.; J. Braz. Chem. Soc. 2015, 26, 1466.

7. Zahedi, P.; Rezaeian, I.; Ranaei-Siadat, S.-O. O.; Jafari, S.-H. H.; Supaphol, P.; Polymers Advanced Technologies 2010, 21, 77.

8. Miguel, S. P.; Figueira, D. R.; Simões, D.; Ribeiro, M. P.; Coutinho, P.; Ferreira, P.; Correia, I. J.; Colloids Surf., B 2018, 169, 60.

9. Su, S.; Bedir, T.; Kalkandelen, C.; Ozan Başar, A.; Turkoğlu Şaşmazel, H.; Bulent Ustundag, C.; Sengor, M.; Gunduz, O.; Eur. Polym. J. 2021, 142,

10. Guellis, C.; Rossin, A. R. S.; Bessegato, G. G.; Dragunski, D. C.; Bariccatti, R. A.; Lindino, C. A.; J. Braz. Chem. Soc. 2021, 5, 1040

11. De Castro, J. G.; Rodrigues, B. V. M.; Ricci, R.; Costa, M. M.; Ribeiro, A. F. C.; Marciano, F. R.; Lobo, A. O.; RSC Adv. 2016, 6, 32615.

12. Carvalho, B. M.; Pellá, M. C. G.; Hardt, J. C.; de Souza Rossin, A. R.; Tonet, A.; Ilipronti, T.; Caetano, J.; Dragunski, D. C. E.; J. Mol. Liq. 2021, 325, 115206.

13. Popov Pereira da Cunha, M. D.; Caracciolo, P. C.; Abraham, G. A.; Curr. Opin. Biomed. Eng. 2020.

14. Volokhova, A. A.; Kudryavtseva, V. L.; Spiridonova, T. I.; Kolesnik, I.; Goreninskii, S. I.; Sazonov, R. V.; Remnev, G. E.; Tverdokhlebov, S. I.; Mater. Today Commun. 2021, 26, 102134.

15. Zięba, M.; Włodarczyk, J.; Gupta, A.; Pastusiak, M.; Chaber, P.; Janeczek, H.; Musioł, M.; Sikorska, W.; Kaczmarczyk, B.; Radecka, I.; Kowalczuk, M.; Savickas, A.; Savickiene, N.; Adamus, G.; Eur. Polym. J. 2021, 147.

16. Wang, B.; Xin, T.; Shen, L.; Zhang, K.; Zhang, D.; Zhang, H.; Liu, J.; Chen, B.; Cui, W.; Shu, Y.; Chem. Eng. J. 2021, 419.

17. Haji Mohammadi Gohari, P.; Haghbin Nazarpak, M.; Solati-Hashjin, M.; Mater. Today Commun. 2021, 27, 102287.

18. Santana-Melo, G. F.; Rodrigues, B. V. M.; da Silva, E.; Ricci, R.; Marciano, F. R.; Webster, T. J.; Vasconcellos, L. M. R.; Lobo, A. O.; Colloids Surf., B 2017, 155, 544.
19. Schneider, R.; Mercante, L. A.; Andre, R. S.; Brandão, H. de M.; Mattoso, L. H. C.; Correa, D. S.; React. Funct. Polym. 2018, 132, 26.

20. Pagno, V.; Módenes, A. N.; Dragunski, D. C.; Fiorentin-Ferrari, L. D.; Caetano, J.; Guellis, C.; Gonçalves, B. C.; dos Anjos, E. V.; Pagno, F.; Martinelli, V.; J. Environ. Chem. Eng. 2020, 8.

21. Nofar, M.; Salehiyan, R.; Ciftci, U.; Jalali, A.; Durmuş, A.; Composites B: Eng 2020, 182. https://doi.org/10.1016/j. compositesb.2019.107661.

22. Wang, K.; Huang, J.; J. Phys. Chem. Solids 2019, 126, 155.

23. Jian, J.; Xiangbin, Z.; Xianbo, H.; Adv. Ind. Eng. Polym. Res. 2020, 3, 19.

24. Ghosal, K.; Manakhov, A.; Zajíčková, L.; Thomas, S.; AAPS PharmSciTech 2017, 18, 72.

25. Asawahame, C.; Sutjarittangtham, K.; Eitssayeam, S.; Tragoolpua, Y.; Sirithunyalug, B.; Sirithunyalug, J.; AAPS PharmSciTech 2014, 16, 182.

26. Saeed, S. M.; Mirzadeh, H.; Zandi, M.; Barzin, J.; Prog. Biomater. 2017, 6,39 .

27. Machado, B. R.; Roberto, S. B.; Bonafé, E. G.; Camargo, S. E. A.; Camargo, C. H. R.; Popat, K. C.; Kipper, M. J.; Martins, A. F.; J. Braz. Chem. Soc. 2019, 30, 1741.

28. Cunha, I. B. S.; Sawaya, A. C. H. F.; Caetano, F. M.; Shimizu, M. T.; Marcucci, M. C.; Drezza, F. T.; Povia, G. S.; Carvalho, P. D. O.; J. Braz. Chem. Soc. 2004, 15, 964.

29. Cottica, S. M.; Sawaya, A. C. H. F.; Eberlin, M. N.; Franco, S. L.; Zeoula, L. M.; Visentainer, J. V.; J. Braz. Chem. Soc. 2011, 22, 929.

30. Bankova, V.; Popova, M.; Trusheva, B.; Macedonian Journal of Chemistry and Chemical Engineering 2016, 35, 1 .

31. Sanpa, S.; Sutjarittangtham, K.; Tunkasiri, T.; Eitssayeam, S.; Chantawannakul, P.; Adv. Mater. Res. 2012, 506, 537.

32. Pant, K.; Thakur, M.; Chopra, H. K.; Nanda, V.; Javed Ansari, M.; Pietramellara, G.; Pathan, S. I.; Alharbi, S. A.; Almoallim, H. S.; Datta, R.; J. King Saud Univ., Sci. 2021, 33, 101405.

33. Zancanela, D. C.; Funari, C. S.; Herculano, R. D.; Mello, V. M.; Rodrigues, C. M.; Borges, F. A.; de Barros, N. R.; Marcos, C. M.; Almeida, A. M. F.; Guastaldi, A. C.; Mater. Sci. Eng., C 2018, 97, 576.

34. Tong Kong, Y.; Veloo Kutty, R.; Mater. Today Proc. 2021.

35. Kim, J. I.; Pant, H. R.; Sim, H. J.; Lee, K. M.; Kim, C. S.; Mater. Sci. Eng., C 2014, 44, 52.

36. Eskandarinia, A.; Kefayat, A.; Gharakhloo, M.; Agheb, M.; Khodabakhshi, D.; Khorshidi, M.; Sheikhmoradi, V.; Rafienia, M.; Salehi, H.; Int. J. Biol. Macromol. 2020, 149, 467.

37. Sharaf, S.; El-Naggar, M. E.; Int. J. Biol. Macromol. 2019, 133, 583.

38. Goes, A. M.; Carvalho, S.; Oréfice, R. L.; Avérous, L.; Custódio, T. A.; Pimenta, J. G.; De B. Souza, M.; Branciforti, M. C.; Bretas, R. E. S. S.; Polímeros 2012, 22, 34.

39. Kargarzadeh, H.; Galeski, A.; Pawlak, A.; Polymer (Guildf). 2020, 203, 122748.

40. Rossin, A. R. de S.; Caetano, J.; Zanella, H. G.; Bariccatti, R. A.; Gaffo, L.; Muniz, E. C.; Caetano, W.; Stolf, S. F.; Dragunski, D. C.; J. Therm. Anal. Calorim. 2021, 1.

41. Bilginer, R.; Yildiz, A. A.; Mater. Lett. 2020, 128191.

42. Ramakrishna, S.; Fujihara, K.; Teo, W.-E.; Lim, T.-C.; Ma, Z.; World Scientific Publishing Co. Pte. Ltd: New Jersey, London, Singapore, Beijing, Shanghai, Hong Kong, Taipei, Chennai, 2005.

43. Rossin, A. R. S.; Oliveira E. L.; Moraes, F. A. P.; Junior, R. C.; Scheidt, D. T.; Caetano, W.; Hioka, N.; Dragunski, D. C.; Quim. Nova 2020, 43, 613.

44. Longo, E.; de Almeida La Porta, F.; Recent Advances in Complex Functional Materials, Springer: New York, 2017.

45. Shao, H.; Yu, X.; Lin, T.; Peng, J.; Wang, A.; Zhang, Z.; Zhang, Y.; Liu, S.; Zhao, M.; Ceram. Int. 2020, 46, 13082.

46. Milovac, D.; Gallego Ferrer, G.; Ivankovic, M.; Ivankovic, H.; Mater. Sci. Eng. C 2014, 34, 437. 
47. Sellami, F.; Kebiche-Senhadji, O.; Marais, S.; Couvrat, N.; Fatyeyeva, K.; React. Funct. Polym. 2019, 139, 120.

48. Silverstein, M. S.; Webster, X. F.; Kiemle, J. D.; Spectrometric Identification of Organic Compounds, $7^{\text {th }}$ ed., Wiley: Hoboken, 2005.

49. Patrício, T.; Bártolo, P.; Procedia Eng. 2013, 59, 292.

50. Sousa, F. M.; Costa, A. R. M.; Reul, L. T. A.; Cavalcanti, F. B.; Carvalho, L. H.; Almeida, T. G.; Canedo, E. L.; Polym. Bull. 2019, 76, 1573.
51. Weng, Y.-X. X.; Jin, Y.-J. J.; Meng, Q.-Y. Y.; Wang, L.; Zhang, M.; Wang, Y.-Z. Z. B.; Polym. Test. 2013, 32, 918.

52. Torgbo, S.; Sukyai, P.; Polym. Degrad. Stab. 2020, 179, 109232.

53. Yayan, J.; Ghebremedhin, B.; Rasche, K.; PLoS One 2015, 10.

54. Costa, S. F.; Gales, A.; Machado, A. M. O.; Padronização dos Testes de Sensibilidade a Antimicrobianos por Disco-difusão, 8a. ed, Anvisa: São Paulo, 2006. 